\title{
Synthesis of the C5-C17 fragment of saliniketal A
}

\section{Carla Cristina Perez and Luiz Carlos Dias*}

\section{Chemistry Institute, State University of Campinas, UNICAMP, C.P. 6154, Campinas, SP, (Brazil)} *e-mail: Idias@iqm.unicamp.br

Keywords: saliniketal, polyketides, ornithine decarboxylase.

\section{INTRODUCTION}

The marine-derived saliniketals $A(1)$ and $B(2)$ were isolated from the marine actinomycete Salinispora arenicola by Fenical and co-workers. ${ }^{1 a}$ Their structures were confirmed by total synthesis in $2007 .{ }^{1 b}$ We wish to describe here our synthetic strategy for the synthesis of saliniketal $A$.

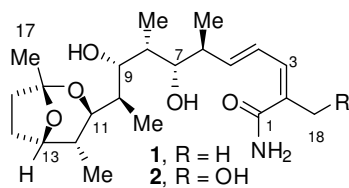

\section{RESULTS AND DISCUSSION}

Our approach began with an asymmetric aldol addition of the boron enolate derived from oxazolidinone (S)-4 with aldehyde $(R)-\mathbf{3}$ to give aldol adduct 5 (75\%, ds 95:5). Transamidation followed by protection of the alcohol functionality provided Weinreb amide 6 (80\%, 2 steps), which was treated with $\mathrm{EtMgCl}$ providing 7 (75\%). Three different attempts of a double stereodifferentiating aldol reaction were performed using diferent Lewis acids (Table 1) and a selectivity inversion was observed when $\mathrm{Ti}(\mathrm{PrO}) \mathrm{Cl}_{3}$ was employed. The relative stereochemistry was assigned by applying the method of Murata and co-workers's for conformational analysis of acyclic systems, based on proton-carbon coupling constants. ${ }^{2-4}$ These results allowed us to attribute the desired 6,7-anti and 7,8-syn configuration for compound $\mathbf{1 0}$ (Scheme 1). Stereoselective reduction of $\beta$ hydroxy ketone 10 delivered anti-diol 11 in 58\% yield and 85:15 diastereoselectivity. The conversion of diol to the corresponding isopropylidene acetal according to the Rychnovsky methodology, ${ }^{5}$ confirmed the 1,3-syn relative stereochemistry. Removal of the PMB group and Swern oxidation provided aldehyde 14, which was treated with the corresponding Grignard reagent providing 15 in $58 \%$ yield for the two steps.

Table 1. Lewis acids used in aldol reactions between 7 and 8.

\begin{tabular}{lll}
\hline Lewis Ac. & Yield (2 steps) & $d r(\mathbf{9 : 1 0})$ \\
\hline $\mathrm{TiCl}_{4}$ & $52 \%$ & $72: 28$ \\
$\mathrm{SnCl}_{4}$ & $58 \%$ & $83: 17$ \\
$\mathrm{Ti}_{(}(\mathrm{PrO}) \mathrm{Cl}_{3}$ & $60 \%$ & $15: 85$ \\
\hline
\end{tabular}

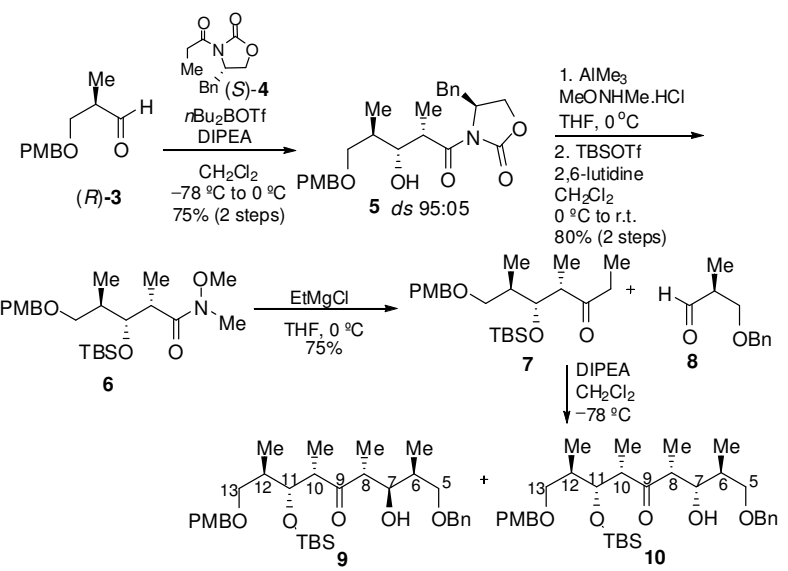

Scheme 1. Preparation of $\mathrm{C} 5-\mathrm{C} 13$ fragment.

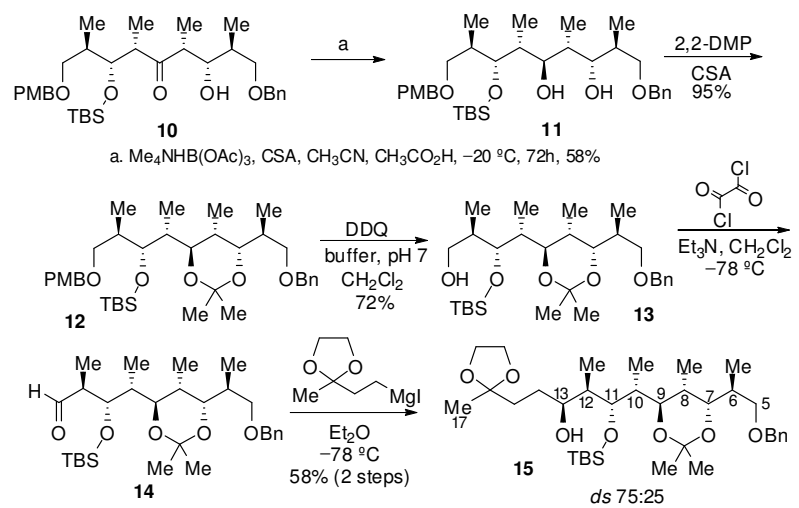

Scheme 2. Preparation of $\mathrm{C} 5-\mathrm{C} 17$ fragment.

\section{CONCLUSION}

The synthesis of the $\mathrm{C} 5-\mathrm{C} 17$ fragment (15) of saliniketal was achieved in 11 steps and $6 \%$ overall yield.

\section{ACKNOWLEDGEMENTS}

We are grateful to FAPESP, CNPq, and CAPES.

\section{REFERENCES}

1 (a) Willian, P.G.; Asolkar, R.N.; Kondratyuk, T.; Pezzuto, J.M.; Jensen, P.R.; Fenical, W. J. Nat. Prod. 2007, 70, 83-88. (b) Paterson, I.; Razzak. M.; Anderson, E.A. Org. Lett. 2008, 10, 3295-3298

2 Matsomuri, N.; Kaneno, D.; Murata, M.; Nakamura, H.;

Tachibama, K. J. Org. Chem. 1999, 64, 866-876.

${ }^{3}$ The measurement of coupling constants ${ }^{n} J_{C H}$ were made using HSQC-TOCSY-IPAP experiments in collaboration with Professor Cláudio Tormena at Unicamp.

${ }^{4}$ Parella, T.; Belloc, J.; Sánchez-Ferrando, F.; Virgili, A. Magn. Reson. Chem. 1998, 36, $715-719$.

${ }^{5}$ Rychnovsky, S.D.; Skalitzky, D.J. Tetrahedron Lett. 1990, 31, 945.

$14^{\text {th }}$ Brazilian Meeting on Organic Synthesis $-14^{\text {th }}$ BMOS - September 01-05, 2011-Brasilia, Brazil 